\title{
POR AMOR ÀS LETRAS
}

\section{Lucia Castello Branco}

UFMG

Para Ângela, Eneida e Ruth, pelas primeiras letras.

"Vereis que, pouco a pouco, as letras vão rolar do próprio nome:

amor sem $m$.

amor sem o.

amor sem $\mathrm{r}$.

amor sem a."

(Maria Gabriela Llansol)

Gostaria de evocar, já de início, depois dessas letras que, em Llansol, rolam do próprio nome, o "mistério nas letras", tantas vezes aludido por Mallarmé e retomado por Blanchot, em diversos de seus ensaios:

Existe algo como as Letras... Muito poucos levantaram este enigma, que ensombra, da maneira como o faço, para o tarde, tomado de repentina dúvida a respeito daquilo de que gostaria de falar impulsivamente. ${ }^{1}$

Gostaria de evocar aqui esse "mistério", porque é ele o que ainda sobrevive - o que resta -, quando me ponho a pensar na Faculdade de Letras como uma casa em que me foi dado um abrigo prolongado: primeiro, como aluna de graduação, de 1974 a 1979; depois como aluna da primeira turma do Doutorado em Literatura Comparada, de 1985 a 1990; e ainda como professora da graduação, de 1984 até hoje, e professora da pósgraduação, desde 1990, com frequente atuação nas linhas de pesquisa Literatura e Psicanálise e Poéticas da Modernidade.

Sim, porque foi pelas letras, por amor às letras, que aqui cheguei e que aqui permaneci. E assim já teria sido desde antes, mesmo antes de prestar o exame para o vestibular, quando então uma charge no jornal "Pasquim" - em que se via um sujeito muito concentrado, esculpindo uma letra, e onde se lia, abaixo: "Estudante de Letras, estudando" - não me faria nem rir, nem chorar, mas antes levar a sério esse ofício.

Devo confessar, então, que não foi exatamente por vocação ao magistério que decidi estudar as letras e me tornar professora. E talvez não seja possível sustentar, até hoje, que aqui permaneci por acreditar ser este - a casa das Letras - o melhor lugar para abrigar um escritor. Esses sonhos - tanto o de que a Faculdade de Letras possa vir a ser a morada dos escritores, quanto o de que os escritores possam se reunir assim, numa só morada - ruíram tão rapidamente quanto as letras rolaram de seu próprio nome.

${ }^{1}$ MALLARMÉ citado por BLANCHOT. Para onde vai a literatura?, p. 244. 
Mas talvez o que tenha permanecido, como um enigma, seja precisamente a letra - essa "pedra dura ao luar", ${ }^{2}$ a dizer, sempre, que algo de muito concreto poderia ser feito com ela. O que, exatamente?

Em "O espírito da letra", texto de 1970, em que Roland Barthes se debruça sobre a enciclopédia de Massin, algumas importantes perguntas acerca desse "mistério" são arroladas. Uma delas, que nos parece quase retórica, ainda se mantém na atualidade: "A escrita é feita de letras. É uma evidência. Mas as letras, de que são feitas?"3

Essa pergunta, tão enigmática quanto aparentemente superficial, merece, no contexto do ensaio de Barthes, uma resposta quase evasiva:

Podemos procurar uma resposta desconhecida, no que se relaciona ao alfabeto; mas podemos igualmente utilizar a pergunta para desviar o problema de origem, pensar em uma conceptualização progressiva da relação flutuante, cuja fixação determinamos sempre de maneira abusiva. No Oriente, nessa civilização ideográfica, o que é traçado é o que está entre a escrita e a pintura, sem que uma prevaleça sobre a outra: o que permite desmentir esta absurda lei de filiação, que é nossa lei, paterna, civil, mental, científica: lei segregacionista em nome da qual separamos grafistas de pintores, romancistas de poetas, mas a escrita é uma: o descontínuo que é sua característica maior faz de tudo o que escrevemos, pintamos, traçamos, um único texto. ${ }^{4}$

Creio que não é apenas por uma aproximação ao campo das artes plásticas que uma letra - esta que compõe a escrita - se define. E também parece-me claro que, para Roland Barthes, essa aproximação é insuficiente, já que, na abertura do ensaio, ele anuciara uma ambição maior - a de responder não exatamente sobre a matéria de que são feitas as letras, mas sobre sua função: "As letras servem para compor palavras? Sem dúvida, mas também para algo mais. O quê? Abecedários."

Fiquemos, por enquanto, com esse "algo mais". E, se não nos contentamos com a rápida resposta de Barthes, não é porque desmerecemos a função dos "abecedários" que tantas vezes serviram ao próprio autor quase que como um método, na composição de seus textos em fragmentos -, mas porque desconfiamos que esse "algo mais" encerra um mistério - precisamente o que Mallarmé viria a chamar de "o mistério nas letras".

O fato é que a letra não chegou a tomar corpo de conceito até hoje, seja no campo da linguística, seja no campo dos estudos literários propriamente ditos. ${ }^{6}$ Talvez apenas na psicanálise, a partir de Lacan, e, evidentemente, na matemática e na lógica, a letra tenha alcançado o estatuto de um conceito. Mesmo assim, é a partir do que se convencionou

\footnotetext{
${ }^{2}$ Sobre essa figura da "pedra dura ao luar", ver LLANSOL. O sonho de que temos a linguagem, p. 18.

${ }^{3}$ BARTHES. O espírito da letra, p. 96.

${ }^{4}$ BARTHES. O espírito da letra, p. 96.

${ }^{5}$ BARTHES. O espírito da letra, p. 94.

${ }^{6}$ É preciso reconhecer que, na Faculdade de Letras da UFMG, são os professores que atuam na linha de pesquisa Literatura e Psicanálise os que têm se ocupado mais diretamente da questão da letra. Dentre as tentativas nessa direção, permito-me citar um de meus livros - Os absolutamente sós: Llansol - a letra - Lacan e a tese de Doutorado em Literatura Comparada de Ram Avraham Mandil, Os efeitos da letra: Lacan leitor de Joyce. Também os trabalhos de Ruth Silviano Brandão, sobre a escrita e a representação, e de Ana Maria Clark Peres, sobre o estilo, são atravessados pela tentativa de formalizar, a partir de uma articulação com a Psicanálise, o conceito de letra.
} 
chamar de "segundo Lacan" (entendendo-se, aí, um segundo momento no ensino de Lacan) que podemos separar, com alguma precisão, os conceitos de letra e de significante. ${ }^{?}$

No campo da literatura, contudo, vemos que o "mistério nas letras" parece ocupar menos os teóricos que os próprios poetas e escritores em geral. Estes, sim, de alguma maneira, estão fadados a lidar com esse "mistério", e alguns se sentem mesmo convocados a discorrer sobre ele. Digamos que é no cerne desse mistério que se realiza todo o projeto dos concretistas. Entretanto - e o primoroso trabalho da poeta, artista plástica e teórica portuguesa Ana Hatherly o demonstra, cabalmente - o concretismo não começa propriamente com os poetas concretos, mas muito antes.

Talvez se possa dizer que o concretismo começa com a descoberta das letras, e seu mistério. Pois, afinal, como observa Ana Hatherly, as letras, desde a sua origem, sempre estiveram relacionadas à prática mágico-mística, "que considera a meditação sobre o alfabeto como uma via para o conhecimento do nome das coisas e da criação, ou seja, o conhecimento de Deus."

Não me parece que o desejo de Mallarmé - e mesmo sua "crise espiritual", transposta para a literatura como a "crise do verso" - estivesse longe do desejo do "conhecimento do nome das coisas e da criação". ${ }^{9}$ Entretanto, sabemos que para alguns, como Mallarmé, não é exatamente do inefável que se trata, mas antes da matéria das letras, que se faz mistério justamente quando mais delas nos aproximamos, em sua concretude. Porque, tal qual a literatura, a essência das letras parece residir em seu desaparecimento:

O mistério nas letras é sem dúvida de tal natureza que é degradado se respeitado e escapa quando agarrado. Para quem o honra de longe, chamando-o de segredo e de inefável, ele se faz objeto de nojo, algo perfeitamente vulgar. E quem dele se aproxima para explicá-lo só encontra o que se esquiva e só busca o que foge. ${ }^{10}$

Para um poeta, sabemos, esse não será nunca um mistério qualquer, mas precisamente o mistério que faz, das letras, literatura, essa linguagem que nunca está "apenas em repouso", que nunca é "definitivamente feita, imobilizada e morta", mas que aspira ao paradoxo de uma língua que, "constituindo-se como nascente, quisesse por isso mesmo ser definitivamente feita, ser perfeita". ${ }^{11}$

Talvez, então, hoje eu pudesse dizer que o encanto da charge que me fora apresentada pelo Pasquim, meses antes que eu me decidisse por tentar o vestibular para a Faculdade de Letras, residisse nisto: no paradoxo de uma língua em movimento, pousada, por um instante, nas mãos daquele que julga detê-la, retê-la, inteira, intacta, perfeita.

Sabemos que, se não é da perfeição da forma que a literatura hoje se ocupa, é ainda como "responsabilidade da forma" que podemos concebê-la. ${ }^{12}$ E talvez a letra

\footnotetext{
${ }^{7}$ A esse respeito, ver MILNER. A obra clara: Lacan, a ciência e a filosofia.

${ }^{8}$ HATHERLY. A experiência do prodígio: bases teóricas e antologia de textos visuais portugueses dos séculos XVII e XVIII, p. 149.

${ }^{9}$ BLANCHOT. O livro por vir, p. 243-244.

${ }^{10}$ BLANCHOT. O mistério nas letras, p. 48.

${ }^{11}$ BLANCHOT. O mistério nas letras, p. 61.

${ }^{12}$ Refiro-me, aqui, à concepção de Barthes em Aula.
} 
possa finalmente ser pensada, no campo dos estudos literários, como um grão, como o grão dessa responsabilidade, aquilo que permite que a linguagem tome forma no informe, tome sentido no insensato, como no poema de Éluard: "Prendre forme dans l'informel Prendre empreinte dans le flou/Prendre sens dans l'insensé". ${ }^{13}$

Não terá sido por acaso que, por amor às letras, fui encontrar esse grão nos textos de poetas - Manoel de Barros, dentre uns - e de loucos - Arthur Bispo do Rosário, dentre outros. Com ambos aprendi que o mistério nas letras talvez resida no fato de elas não terem mistério nenhum, como teria dito, acerca do "sentido íntimo das coisas", o poeta Alberto Caeiro. ${ }^{14}$

E ainda aí (eis, talvez, o "algo mais" a que se refere Barthes, em seu ensaio) são as letras que restam, quando nada mais resta da leitura de um poema, ou da escrita de um texto que se propõe a falar de seu mistério.

É assim que imagino essa Casa das Letras que há trinta e quatro anos me tem abrigado e abriga outros que, se aqui se encontram, só podem se reunir um a um, como letras singulares de um abecedário: uma casa da qual, apagadas as últimas luzes, o que restará são as paredes onde reinam, ainda, as letras, como uma "profusão amarga de sinais". ${ }^{15}$

E, se já não podemos ler esses sinais - pois uma letra não se lê -, podemos, quem sabe, escrevê-los, desenhá-los, soletrá-los. Gosto de pensar, hoje, que talvez tenha sido por essa chance rara - a de poder só letra -los - que um dia vim parar aqui.

A

\section{REFERÊNCIAS}

BARTHES, Roland. O espírito da letra. In: Oóbvio e o obtuso. Rio de Janeiro: Nova Fronteira, 1990. BARTHES, Roland. Aula. São Paulo: Cltrix, s.d.

BLANCHOT, Maurice. Para onde vai a literatura? In: . O livro por vir. Lisboa: Relógio D’Água, 1984. BLANCHOT, Maurice. O mistério nas letras. In: . A parte do fogo. Rio de Janeiro: Rocco, 1997.

BRANCO, Lúcia Castello. Os absolutamente sós: Llansol - a letra - Lacan. Belo Horizonte: Autêntica, 2000.

CAEIRO, Alberto. O guardador de rebanhos. Poema V. In: PESSOA, Fernando. Obra poética. Rio de Janeiro: Nova Aguilar, 1997.

CAEIRO, Alberto. Poema XXXIX. In: PESSOA, Fernando. Obra poética. Rio de Janeiro: Nova Aguilar, 1997.

HATHERLY, Ana. A experiência do prodígio: bases teóricas e antologia de textos visuais portugueses dos séculos XVII e XVIII. Lisboa: Imprensa Oficial-Casa da Moeda, 1983.

LLANSOL, Maria Gabriela. O sonho de que temos a linguagem. Revista Colóquio-Letra, Lisboa, FUNDABENKIAN, n. 143/144, p. 18, jan-jun 1997.

MANDIL, Ram Avraham. Os efeitos da letra: Lacan leitor de Joyce. Rio de Janeiro: Contra Capa, 2003. MILNER, Jean-Claude. A obra clara: Lacan, a ciência e a filosofia. Rio de Janeiro: Zahar, 1996.

\footnotetext{
${ }^{13}$ ÉLUARD, citado por BLANCHOT. O mistério nas letras, p. 64.

${ }^{14}$ CAEIRO. O guardador de rebanhos. Poema V, p. 207-208. São estes os versos de Caeiro: "O único sentido íntimo das cousas/É elas não terem sentido íntimo nenhum". Ou, ainda, no poema XXXIX, à p. 223: "O mistério das cousas, onde está ele? (...)/ Porque o único sentido oculto das cousas/É elas não terem sentido oculto nenhum",

${ }^{15}$ LLANSOL. O sonho de que temos a linguagem, p. 18.
} 